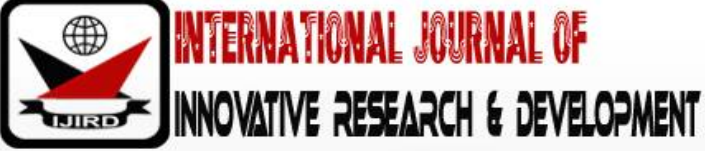

ISSN 2278 - 0211 (Online)

\section{Comparative Study of the In-Vitro Dissolution Profile of Griseofulvin Tablets Formulated with Kolliphor HS-15, Sodium Lauryl Sulphate and PEG 4000}

\begin{tabular}{c}
\hline Ifeoma Cynthia Ekenna \\
Lecturer, Department of Pharmaceutics and Pharmaceutical Technology, \\
University of Port Nigeria \\
Ogbonna Okorie \\
Professor, Department of Pharmaceutics and Pharmaceutical Technology, \\
University Of Port, Nigeria \\
Sabinus I. Ofoefule \\
Professor, Department of Pharmaceutical Technology and Industrial Pharmacy, \\
University of Nigeria, Nigeria
\end{tabular}

\begin{abstract}
:
Objective: Griseofulvin, an antifungal drug belongs to the class II of the Biopharmaceutical Classification System (BCS). It has the characteristics of poor aqueous solubility and good lipid permeability. Attempts have been made severally to improve the solubility and hence release of griseofulvin from different dosage forms. The study aimed to evaluate the effect of the different surfactants- Kolliphor ${ }^{\circledR}$ HS-15 (KHS 15), Sodium lauryl sulphate (SLS) and Polyethylene glycol (PEG) 4000 on the in-vitro dissolution and release of griseofulvin from compressed tablets.

Method: Griseofulvin tablets were formulated with different concentrations of the surfactants and a control batch without surfactants using the wet granulation method. Dissolution test was carried out on the formulated tablets in $1000 \mathrm{ml}$ of $80 \%$ methanol. Comparisons were made amongst the dissolution profiles of the formulated tablets and a commercial brand using model dependent and independent methods. MANOVA was used in the analysis of percent drug release of the tablets.

Result: All the different methods of comparing in-vitro dissolution are important. The tablets formulated with surfactants had better dissolution profiles than the control batch. Tablets containing PEG 4000 exhibited the best dissolution. The PEG 4000 containing tablet batches exhibited anomalous mechanism of drug release while the other batches of griseofulvin tablets including the commercial brand all exhibited quasi- Fickian mechanism of drug release.

Conclusion: PEG 4000 containing tablets had the best dissolution profile. At the concentrations used, SLS and Kolliphor ${ }^{\circledR}$ HS 15 only had marginal improvement of griseofulvin dissolution compared with the control batch.
\end{abstract}

Keywords: Griseofulv in, dissolution, similarity factor, SLS, PEG 4000, Kolliphor ${ }^{\circledR}$ HS 15, kinetic models

\section{Introduction}

Griseofulvin is a fungistatic drug used in treating ringworm and dermatophyte infections. It is administered orally and is used in treating stubborn infections involving the external skin layer(Beers et al.,, 2003; WHO, 2001). Griseofulvin acts by binding microtubular proteins that are needed for mitosis. After its administration, griseofulvin deposits on the skin, by tightly binding on the keratin precursor cells. Its strong attachment to these precursor cells found on the skin makes such skin cells impervious / very resistant to further fungal attack (Schlossberg \& Samuel, 2017; WHO, 2001). It belongs to the Biopharmaceutical Classification System (BCS) II having poor aqueous solubility and high lipid permeability. Taking griseofulvin with a diet high in fat content improves its bioavailability greatly (Schlossberg \& Samuel, 2017).

For poorly, soluble drug like Griseofulvin, the rate-determining step for absorption is the dissolution of the drug(Sakina, Usman, \& Naeem, 2013), A drug must first be dissolved before it gets absorbed into the human system, therefore, the poor solubility of griseofulvin has been an issue of great interest in the scientific community as it poses a problem in the bioavailability of the drug. Griseofulvin has been found to have a variable and incomplete absorption from the gastrointestinal tract (GIT)(Khalafalla, Elgholmy, \& Khalil, 1980; Ong, Ming, Lee, \& Yuen, 2016). Griseofulvin has a bioavailability of about 50\% in 30 to 40 hours(Chiou \& Riegelman, 1971; "The Pharmaceutical Codex",1979). The erratic and poor bioavailability of the drug has resulted in high dosing of the drug even though it is prepared as micro-sized and ultra-micro sized particles. 
Several methods have been used in improving the dissolution of griseofulvin(Chaumeil, 1998; Chiang et al.,, 2013; Madelung, Bertelsen, Jacobsen, Müllertz, \& Østergaard, 2017; McGinity, Ku, Bodmeier, \& Harris, 1985; Nyström \& Westerberg, 1986; Ong et al., 2016; Phanchaxari, Kaushik, \& Telsang, 2011; Zili, Sfar, \& Fessi, 2005). In several researches, surfactants such as sodium lauryl sulphate (SLS) have been used in improving the dissolution of griseofulvin when used in solid dispersion formulations (Chiang et al., 2013; El-Badry, Fetih, \& Fathy, 2009), by addition into dissolution medium in order to achieve sink condition (Granero, Ramachandran, \& Amidon, 2005; Razvi, Siddiqui, \& Khan, 2005; Sakina et al., 2013), using surfactants in complexation formulations with cyclodextrin(Lee, Lee, Choi, \& Kim, 2001), formulating them as physical mixtures with the active drug(El-Badry et al., 2009). Three (3) general methods can be used to compare in vitro dissolution profile: 1 . Statistical methods (analysis of variance (ANOVA) and multivariate analysis of variance (MANOVA) (Sakina et al., 2013; Yuksel, Kanik, \& Baykara, 2000), 2. Model-independent method (similarity factor (f2),(difference factor (f1) and dissolution efficiency)(Kassaye \& Genete, 2013; Sakina et al., 2013; Soni \& Chotai, 2010; Yuksel et al., 2000) and 3. Model dependent method (Sanford Bolton. , 1997; Yuksel et al., 2000).

This work aimed to evaluate the effect of three polymers - SLS, PEG 4000 and Kolliphor ${ }^{\circledR}$ HS 15 on the in-vitro dissolution of griseofulvin press compressed tablets. The dissolution of griseofulvin from the compressed tablets was compared with a commercial brand of griseofulvin tablet.

\section{Materials and Methods}

\subsection{Materials}

Micronized griseofulvin (Chifeng Pharmaceuticals Co. Ltd, China), Kolliphor ${ }^{\circledR}$ HS-15(BASF, Germany), dimethylformamide (Qualikem), powdered potassium dichromate (JHD, China), PEG 4000 (BDH, England), sodium lauryl sulphate (Lobachem, India), hydrochloric acid (JHD, China), lactose (BDH, England), methanol (JHD, China), freshly distilled water, Mycoxyl -500 ${ }^{\circledR}$ tablets (Bangkok Lab and cosmetics Co. Ltd, Thailand)- the commercial brand used as reference standard.

\subsection{Method}

\subsubsection{Authentication of Sample}

The melting point of the sample was determined using the Electrothermal ${ }^{\circledR}$ melting point apparatus (England). Also, $5 \mathrm{mg}$ quantity of the sample was dissolved in $1 \mathrm{ml}$ of sulphuric acid reagent and about $5 \mathrm{mg}$ of powdered potassium dichromate reagent was added. The development of a dark red solution confirms griseofulvin.

A $0.75 \mathrm{~g}$ quantity of sample was dissolved in dimethylformamide reagent and diluted to $10 \mathrm{ml}$ with the same solvent. Griseofulvin is confirmed by the development of a colourless solution (British Pharmacopoeia, 2009).

\subsubsection{Preparation of Griseofulv in Tablets}

Tablets were prepared using the wet granulation method. The powder mix of griseofulvin, $10 \%$ starch, lactose and the different concentrations of the surfactants - SLS, PEG 4000, Kolliphor ${ }^{\circledR}$ HS 15 (where applicable) were wet massed with $5 \%$ starch mucilage. The wet mass was screened through a $2 \mathrm{~mm}$ aperture sieve and oven-dried at $60{ }^{\circ} \mathrm{C}$ for 2 hours. The dried granules were passed through a $1 \mathrm{~mm}$ aperture screen and dried again. The granules were lubricated with $1 \%$ magnesium stearate and $0.5 \%$ talc before compressing with a single punch, Erweka D- 63150 (GmbH, Germany). The composition of the batches and batch codes are shown in Table 1.

\begin{tabular}{|c|c|c|c|c|c|c|c|c|c|c|}
\hline \multirow[t]{2}{*}{ Ingredients } & \multicolumn{10}{|c|}{ Batch code } \\
\hline & Ctrl & B1 & B2 & B3 & B4 & B5 & B6 & B7 & B8 & B9 \\
\hline Griseofulvin (mg) & 250 & 250 & 250 & 250 & 250 & 250 & 250 & 250 & 250 & 250 \\
\hline $\begin{array}{c}\text { Maize starch as } \\
\text { disintegrant } \\
(\% \mathrm{w} / \mathrm{w})\end{array}$ & 10 & 10 & 10 & 10 & 10 & 10 & 10 & 10 & 10 & 10 \\
\hline $\begin{array}{c}\text { Kolliphor }^{\circledR} \text { HS } 15 \\
(\% \mathrm{w} / \mathrm{w})\end{array}$ & - & 2.5 & 5.0 & 10.0 & - & - & - & - & - & - \\
\hline SLS $(\% \mathrm{w} / \mathrm{w})$ & - & - & - & - & 1 & 1.5 & 2.5 & - & - & - \\
\hline PEG $4000(\% \mathrm{w} / \mathrm{w})$ & - & - & - & - & - & - & - & 6.25 & 12.5 & 15 \\
\hline $\begin{array}{l}\text { Maize Starch as } \\
\text { binder }(\% \text { w } / \mathrm{w})\end{array}$ & 5 & 5 & 5 & 5 & 5 & 5 & 5 & 5 & 5 & 5 \\
\hline $\begin{array}{c}\text { Magnesium sterate } \\
(\% \mathrm{w} / \mathrm{w})\end{array}$ & 1 & 1 & 1 & 1 & 1 & 1 & 1 & 1 & 1 & 1 \\
\hline $\operatorname{Talc}(\% \mathrm{w} / \mathrm{w})$ & 0.5 & 0.5 & 0.5 & 0.5 & 0.5 & 0.5 & 0.5 & 0.5 & 0.5 & 0.5 \\
\hline Lactose q.s (mg). & 365 & 365 & 365 & 365 & 365 & 365 & 365 & 365 & 365 & 365 \\
\hline
\end{tabular}

Table 1: Drug Composition 


\subsubsection{Preparation of Calibration Curve}

A stock solution of griseofulvin / absolute methanol in a ratio of 1:1 containing 100mg of griseofulvin was made. Another stock solution of griseofulvin / $80 \%$ methanol in a ratio of 1:1 containing 100mg of griseofulvin was prepared. Each solution was passed through a UV spectrophotometer and readings were taken at concentrations of $0.1 \%, 0.2 \%$, $0.3 \%, 0.4 \%, 0.5 \%, 0.6 \%, 0.01 \%, 0.02 \%, 0.03 \%, 0.04 \%, 0.05 \%$ and $0.06 \%$ at wavelengths of $291 \mathrm{~nm}$ for the $80 \%$ methanol solution and $292 \mathrm{~nm}$ for the absolute methanol solution. A standard calibration curve was obtained by plotting absorbance against concentration.

\subsubsection{Drug Content Uniformity Test}

Twenty tablets from each batch including the commercial brand were weighed and crushed to powder. Weight of the powder equivalent to $250 \mathrm{mg}$ of griseofulvin was weighed out and dissolved in $250 \mathrm{ml}$ of absolute methanol producing a $1 \mathrm{mg} / \mathrm{ml}$ concentration. The mixture was agitated for one hour, centrifuged for 30 minutes, the supernatant was collected and diluted. The diluted samples were analyzed at wavelengths of $292 \mathrm{~nm}$. The content of active ingredients of each batch was calculated with reference to the calibration curve of griseofulvin previously established.

\subsubsection{In-vitro Dissolution Test}

The dissolution test was carried out according to the method reported byGilbert (2013), with slight modifications. It was carried out on the eight batches of the griseofulvin tablets and the commercial brand, with a control batch labelled as ctrl batch. The dissolution test was carried out in a dissolution apparatus (DA-6D, UK) with $1000 \mathrm{ml}$ of $80 \%$ methanol using the paddle type of dissolution apparatus at $50 \mathrm{rpm}$ at a temperature of $37 \pm 0.5{ }^{\circ} \mathrm{C}$ (Gilbert, 2013). A $10 \mathrm{ml}$ quantity of the medium was withdrawn from the dissolution apparatus at 5min, $10 \mathrm{~min}, 15 \mathrm{~min}, 20 \mathrm{~min}, 30 \mathrm{~min}, 40 \mathrm{~min}, 50 \mathrm{~min}, 60$ $\mathrm{min}, 70 \mathrm{~min}, 80 \mathrm{~min}, 90 \mathrm{~min}, 100 \mathrm{~min}$ and $120 \mathrm{~min}$, filtered (using a Whatman filter paper size $110 \mathrm{~mm}$ ) and diluted with the $80 \%$ methanol. A $10 \mathrm{ml}$ quantity of the medium (80\% methanol) was used to replace the sampled volume at each sampling time. The UV spectrophotometer (Spectrolab model S10, UK) was used to analyze the diluted samples at a wavelength of $291 \mathrm{~nm}$. This was carried out in triplicates.

\subsection{Dissolution Test Comparison}

\subsubsection{Analysis of Variance}

Multivariate analysis of variance (MANOVA) was used to compare dissolution profiles of the batches of drugs; formulated and the commercial brand by analyzing multiple time points of the different dissolution profiles (Costa \& Lobo, 2001). One -way and Two - way ANOVA were also performed. $p \leq 0.05$ was considered significant.

\subsubsection{Model Independent Method}

\subsubsection{Dissolution efficiency $\left(\mathrm{DE}_{120}\right)$}

This is the area under the dissolution curve to a particular time $\left(t_{120}\right)$. It is expressed as the area of the rectangle described by100\% dissolution at the time (120 min). According toAnderson et al., (1998), if at 95\% confidence interval, the mean difference between the dissolution efficiency of a reference standard and a test batch is $\pm 10 \%$, one can say that the dissolution profile of the reference standard and the test batch are similar or equivalent. DE values or equivalent. DE values were calculated from Equation 1.

$$
D E=\frac{\int_{t_{1}}^{t_{2}} y \cdot d t}{y_{100} \cdot\left(t_{2}-t_{1}\right)} \times 100 \%
$$

The one- way ANOVA was used to analyze the dissolution efficiencies of the tablets and also used for comparison of the dissolution profiles of the tablets (Simionato, Petrone, Baldut, Bonafede, \& Segall, 2018).

\subsubsection{Use of the Fit Factors, Difference Factor (f1) and Similarity Factor (f2)}

These were used in comparing the difference or similarity between the dissolution profiles. A difference factor between 0 to 15 indicates similarity between the test batch and the reference batch while a similarity factor (f2) between 50 to 100 indicates similarity between the test batch and the reference batch (Anderson et al., 1998; Islam, Islam, Shahriar, \& Dewan, 2011; Sakina et al., 2013). The similarity factor (f2) is the approved statistic for in-vitro dissolution comparison by SUPAC-IR 1995 (FDA, 2000). The $\mathrm{f} 2$ is more reliable as the presence of a log function in its equation ensures that any difference in dissolution profile is made conspicuous (Júnior et al.,, 2014; Yuksel et al., 2000). f1 and f2 are calculated using Equations 2 and 3.

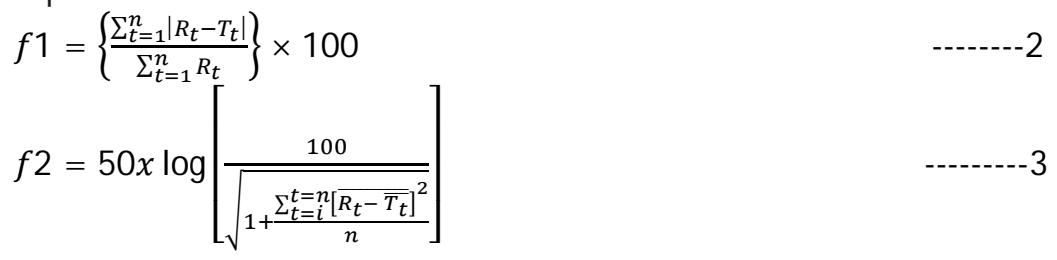

$\mathrm{n}=$ number of time points, $\mathrm{R}_{\mathrm{t}}=$ mean $\%$ API dissolved of reference product at time point $\mathrm{x}, \mathrm{T}_{\mathrm{t}}=$ mean $\%$ API dissolved of test product at time point $\mathrm{x}$ 


\subsubsection{Mean Dissolution time (MDT)}

MDT could be used to measure the rate of a dissolution process. An ANOVA of MDT values of the dissolution profiles could be used for comparison (Simionato et al., 2018). Amount of drug remaining to be dissolved vs time (hour) can be plotted then the Equation 4 used for its calculation (Collier, 1984; Costa \& Lobo, 2001; Podczeck, 1993; Simionato et al., 2018).

MDT $=\frac{\text { Area under the curve }}{\text { Total amount of drug dissolved }}$ $--4$

\subsubsection{Model Dependent Method}

The release kinetics of the griseofulvin tablets were analyzed using the Weibull model and the Korsmeyer model. A one-way ANOVA was used in comparing the parameters of the kinetic models though a t-test has been used in previous researches to analyze the kinetic parameters (Sanford Bolton. , 1997; Yuksel et al., 2000). Equations 5 and 6 relate to the Weibull model and the Korsmeyer model respectively

Weibull $\log [-\ln (1-m)]=\beta \log \left(\mathrm{t}-\mathrm{T}_{i}\right)-\log \alpha$ $------5$

$\mathrm{m}=$ Accumulated fraction of the drug, $\beta=$ shape parameter, $\alpha=$ scale parameter, $\mathrm{T}_{\mathrm{i}}=$ Location parameter/ time lag usually zero, $\mathrm{t}=$ Time in hours

Korsmeyer- Peppas $\quad F=\frac{M_{t}}{M}=K_{m} t^{n}$ $-6$

$\mathrm{F}=$ Fraction of drug released at time $\mathrm{t}, \mathrm{Mt}=$ Amount of drug released at time $\mathrm{t}, \mathrm{M}=$ Total amount of drug in dosage form, $\mathrm{K}_{\mathrm{m}}$ $=$ Kinetic constant, $\mathrm{n}=$ Diffusion/ release exponent, $\mathrm{t}=$ =time in hours.

\subsection{Applications Used}

The excel add-in DD solver version 1 was used to:

- calculate dissolution efficiencies (DE), mean dissolution time (MDT), similarity (f2) and difference factors (f1) and

- fit dissolution profiles to the kinetic models (Costa \& Lobo, 2001; Gao et al.,, 2013; Medina, Salazar, Hurtado, Cortes, \& Domínguez-Ramírez, 2014; Pascoal, da Silva, \& Pinheiro, 2015; Zhang et al.,, 2010).

- Graphpad prism (v.6 for windows) was used for t - test, ANOVA and MANOVA analysis. Statistical significance was always tested at $95 \%$ confidence interval (C.I.) and $\mathrm{p} \leq 0.05$.

\section{Results}

The results of the assay of the griseofulvin tablets are presented in Table 2 . The drug assay ranged from $90.81 \%$ to $103.56 \%$ conforming with the BP requirements (British Pharmacopoeia, 2009).

\begin{tabular}{|c|c|c|}
\hline Batches & Composition & Assay (\%) \\
\hline Brand & Commercial brand (Mycoxyl - 500 & 91.69 \\
\hline Ctrl & 250mg griseofulvin/ no surfactants & 93.68 \\
\hline B1 & 250mg griseofulvin/ 2.5\% Kolliphor ${ }^{\circledR}$ HS 15 & 94.40 \\
\hline B2 & 250mg griseofulvin/ 5\% Kolliphor ${ }^{\circledR}$ HS 15 & $\begin{array}{c}\text { Not tableted (soft and laminating } \\
\text { tablets were formed) }\end{array}$ \\
\hline B3 & 250mg griseofulvin/ 10\% Kolliphor ${ }^{\circledR}$ HS 15 & $\begin{array}{c}\text { Not tableted (soft and laminating } \\
\text { tablets were formed) }\end{array}$ \\
\hline B4 & 250mg griseofulvin / 1\% sodium lauryl sulphate & 90.91 \\
\hline B5 & 250mg griseofulvin / 1.5\% sodium lauryl sulphate & 94.09 \\
\hline B6 & 250mg griseofulvin / 2.5\% sodium lauryl sulphate & 101.09 \\
\hline B7 & 250mg griseofulvin / 6.25\% PEG 4000 & 90.81 \\
\hline B8 & 250mg griseofulvin / 12.5\% PEG 4000 & 103.56 \\
\hline B9 & 250mg griseofulvin / 15\% PEG 4000 & 91.02 \\
\hline
\end{tabular}

Table 2: Drug Content Uniformity

Key: Ctrl (No surfactant), Brand (commercial brand), B1 (2.5\% KHS 15), B4 (1\% SLS), B5 (1.5 SLS), B6 (2\% SLS), B7 (6.25\% PEG 4000), B8 (12.5\% PEG 4000), B9 (15\% PEG 4000)

\subsection{Comparison of In-Vitro Dissolution Profiles}

The dissolution profiles of the eight batches of griseofulvin are presented in Fig. 1. The commercial brand and the batches containing PEG 4000 had better dissolution profile than the other batches. The batch containing $12.5 \%$ of PEG 4000 (B8) had the best dissolution profile. The batches of griseofulvin tablets including the commercial brand exhibited biphasic drug release. 


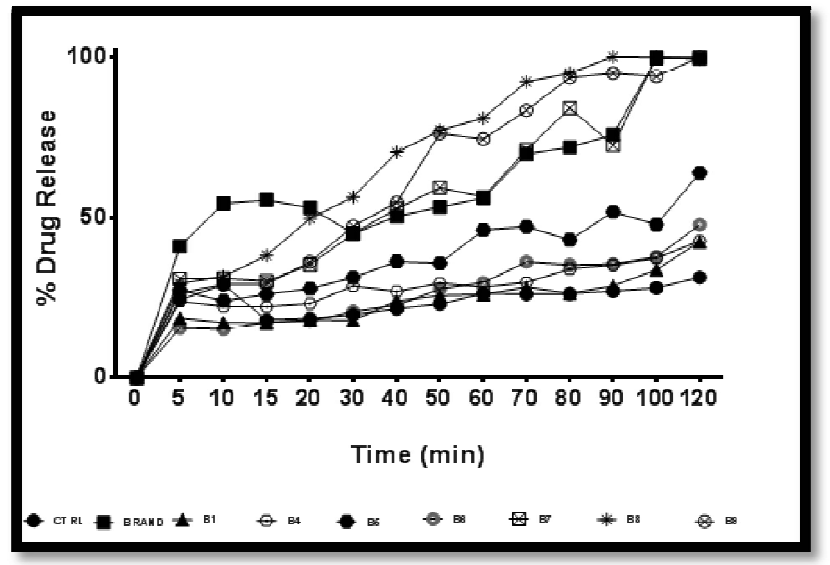

Figure 1: Release Profile of the Formulated Batches of Griseofulvin and the Reference Standard (the Commercial Brand) $(\mathrm{N}=6)$

Key: Ctrl (No Surfactant), Brand (Commercial Brand), B1 (2.5\% KHS 15), B4 (1\% SLS), B5 (1.5 SLS), B6 (2\% SLS), B7 (6.25\% PEG 4000), B8 (12.5\% PEG 4000), B9 (15\% PEG 4000)

\subsubsection{Model Independent Comparison}

\subsubsection{Graphical Comparison}

Comparison of the batch formulated with 2.5\% Kolliphor ${ }^{\circledR}$ HS 15 (B1) with the control batch (Ctrl) and the commercial brand (Brand) shown in Fig. 2a depicts the commercial brand had the best dissolution profile. The control batch and Batch B1 at several points from $15 \mathrm{~min}$ to $120 \mathrm{~min}$ along the graphshowed similarity in dissolution profile as seen by the overlapping points. The commercial brand is also seen to have a better dissolution profile than the SLS formulated griseofulvin tablets as shown in Fig. $2 \mathrm{~b}$. The batch formulated with $2 \%$ of SLS (B6) showed some similarity along points 15, 20, 30 and 40 mins with the control batch in Fig 2b, as those points were overlapping. B6 also shared similarities with tablet formulated with 1\% SLS (B4) at 80 mins to 100mins. The PEG 4000 formulated batches had very comparable dissolution profile with the commercial brand and the batch formulated with $12.5 \%$ of PEG 4000 (B8) showed the best dissolution profile in Fig. 2c. Control batch had the poorest dissolution profile with a wide margin from the other batches in Fig. 2c. At times 5 mins to 10 mins, the PEG 4000 formulated batches had overlapping points with the control batch. From 15 mins to 40 mins B7 and B9 showed similarities in profile. B7, B9 and commercial brand exhibited dissolution profile similarities at 30 mins and 40mins. At 60 mins,70 mins, 90mins and 100 mins, B7 and the commercial brand exhibited similar dissolution profiles.

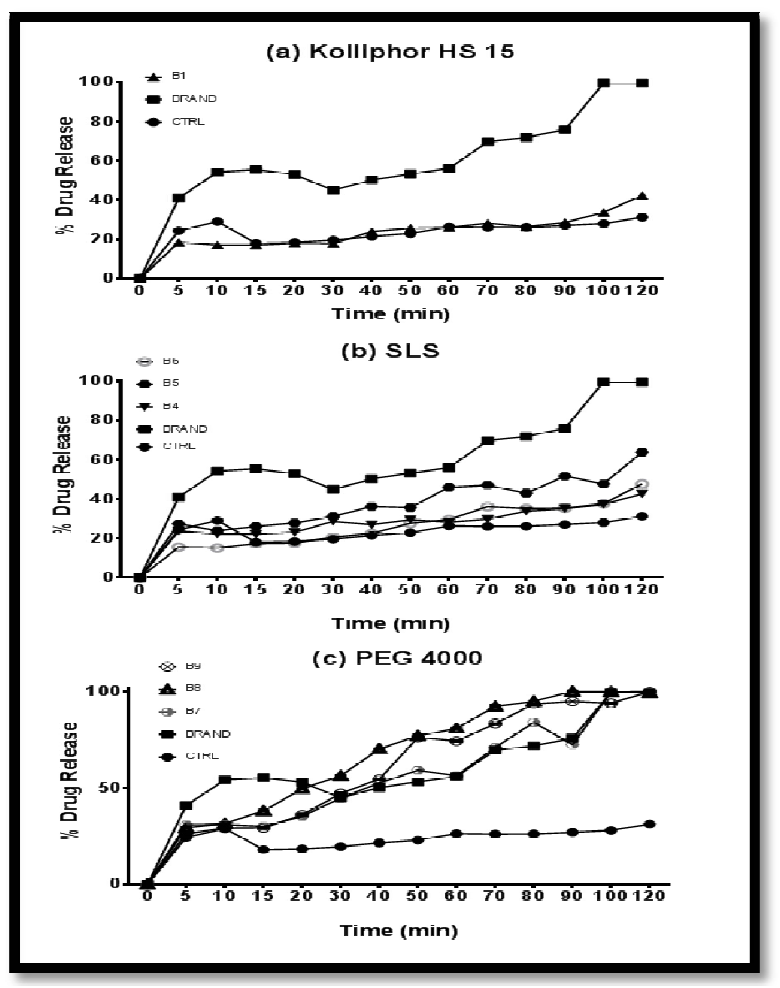

Figure 2: Graphical Comparison of the Dissolution Profiles Amongst

Kolliphor ${ }^{\circledR}$ HS 15, SLS and PEG 4000 with the Control Batch and the Commercial Brand

Key: Ctrl (No Surfactant), Brand (Commercial Brand), B1 (2.5\% KHS 15), B4 (1\% SLS), B5 (1.5 SLS), B6 (2\% SLS), B7 (6.25\% PEG 4000), B8 (12.5\% PEG 4000), B9 (15\% PEG 4000) 


\begin{tabular}{|c|c|c|c|c|c|}
\hline Time (mins) & Uncorrected Fisher's LSD & Mean Diff. & Significant? & Summary & $\begin{array}{c}\text { Individual P } \\
\text { Value }\end{array}$ \\
\hline \multirow[t]{8}{*}{5} & BRAND vs. CTRL & 16.63 & Yes & $* * * *$ & $<0.0001$ \\
\hline & BRAND vs. B1 & 22.47 & Yes & $* * * *$ & $<0.0001$ \\
\hline & BRAND vs. B4 & 17.17 & Yes & $* * * *$ & $<0.0001$ \\
\hline & BRAND vs. B5 & 13.59 & Yes & $* * * *$ & $<0.0001$ \\
\hline & BRAND vs. B6 & 25.44 & Yes & **** & $<0.0001$ \\
\hline & BRAND vs. B7 & 10.05 & Yes & $* * * *$ & $<0.0001$ \\
\hline & BRAND vs. B8 & 11.62 & Yes & $* * * *$ & $<0.0001$ \\
\hline & BRAND vs. B9 & 14.62 & Yes & $* * * *$ & $<0.0001$ \\
\hline \multirow[t]{8}{*}{15} & BRAND vs. CTRL & 37.46 & Yes & **** & $<0.0001$ \\
\hline & BRAND vs. B1 & 38.42 & Yes & $* * * *$ & $<0.0001$ \\
\hline & BRAND vs. B4 & 33.39 & Yes & $* * * *$ & $<0.0001$ \\
\hline & BRAND vs. B5 & 29.36 & Yes & $* * * *$ & $<0.0001$ \\
\hline & BRAND vs. B6 & 38.16 & Yes & $* * * *$ & $<0.0001$ \\
\hline & BRAND vs. B7 & 25.33 & Yes & $* * * *$ & $<0.0001$ \\
\hline & BRAND vs. B8 & 17.35 & Yes & **** & $<0.0001$ \\
\hline & BRAND vs. B9 & 26.19 & Yes & ***** & $<0.0001$ \\
\hline \multirow[t]{8}{*}{30} & BRAND vs. CTRL & 25.34 & Yes & $* * * *$ & $<0.0001$ \\
\hline & BRAND vs. B1 & 27.06 & Yes & ***** & $<0.0001$ \\
\hline & BRAND vs. B4 & 16.33 & Yes & $* * * *$ & $<0.0001$ \\
\hline & BRAND vs. B5 & 13.69 & Yes & $* * * *$ & $<0.0001$ \\
\hline & BRAND vs. B6 & 24.31 & Yes & $* * * *$ & $<0.0001$ \\
\hline & BRAND vs. B7 & 0.04339 & No & Ns & 0.9661 \\
\hline & BRAND vs. B8 & -11.43 & Yes & $* * * *$ & $<0.0001$ \\
\hline & BRAND vs. B9 & -2.293 & Yes & $*$ & 0.0253 \\
\hline \multirow[t]{8}{*}{60} & BRAND vs. CTRL & 29.69 & Yes & ***** & $<0.0001$ \\
\hline & BRAND vs. B1 & 29.98 & Yes & **** & $<0.0001$ \\
\hline & BRAND vs. B4 & 27.8 & Yes & $* * * *$ & $<0.0001$ \\
\hline & BRAND vs. B5 & 9.99 & Yes & $* * * *$ & $<0.0001$ \\
\hline & BRAND vs. B6 & 26.4 & Yes & $* * * *$ & $<0.0001$ \\
\hline & BRAND vs. B7 & -0.3334 & No & Ns & 0.7438 \\
\hline & BRAND vs. B8 & -24.93 & Yes & $* * * *$ & $<0.0001$ \\
\hline & BRAND vs. B9 & -18.35 & Yes & $* * * *$ & $<0.0001$ \\
\hline \multirow[t]{8}{*}{90} & BRAND vs. CTRL & 48.82 & Yes & ***** & $<0.0001$ \\
\hline & BRAND vs. B1 & 47.21 & Yes & $* * * *$ & $<0.0001$ \\
\hline & BRAND vs. B4 & 40.71 & Yes & ***** & $<0.0001$ \\
\hline & BRAND vs. B5 & 24.13 & Yes & $* * * *$ & $<0.0001$ \\
\hline & BRAND vs. B6 & 40.47 & Yes & $* * * *$ & $<0.0001$ \\
\hline & BRAND vs. B7 & 3.327 & Yes & ** & 0.0012 \\
\hline & BRAND vs. B8 & -24.29 & Yes & $* * * *$ & $<0.0001$ \\
\hline & BRAND vs. B9 & -19.17 & Yes & ***** & $<0.0001$ \\
\hline \multirow[t]{8}{*}{120} & BRAND vs. CTRL & 68.27 & Yes & $* * * *$ & $<0.0001$ \\
\hline & BRAND vs. B1 & 57.16 & Yes & **** & $<0.0001$ \\
\hline & BRAND vs. B4 & 56.88 & Yes & ***** & $<0.0001$ \\
\hline & BRAND vs. B5 & 35.66 & Yes & ***** & $<0.0001$ \\
\hline & BRAND vs. B6 & 51.82 & Yes & $* * * *$ & $<0.0001$ \\
\hline & BRAND vs. B7 & -0.4641 & No & Ns & 0.6492 \\
\hline & BRAND vs. B8 & 0.1046 & No & Ns & 0.9183 \\
\hline & BRAND vs. B9 & -0.4241 & No & Ns & 0.6776 \\
\hline
\end{tabular}

Table 3: MANOVA Analysis Comparing the Dissolution Profile of the Commercial Brand with the Formulated Tablets Key: Ctrl (No Surfactant), Brand (Commercial Brand), B1 (2.5\% KHS 15), B4 (1\% SLS),

B5 (1.5 SLS), B6 (2\% SLS), B7 (6.25\% PEG 4000), B8 (12.5\% PEG 4000), B9 (15\% PEG 4000) 


\subsubsection{Analysis of Variance}

Result of the MANOVA performed on the dissolution profiles at $p<0.05$ is shown in Table 3 . At time points 30 mins, 60 mins and 120 mins there were no significant differences in the per cent drug releases from batch B7 and the commercial brand signifying similarity in drug release at those points. From Table 3 and Fig. 2c, it can be observed that at first the commercial brand tested released faster than the PEG 4000 formulated batches but from 30 mins, batches B8 and B9 released faster than the commercial brand.

3.1.1.3. Time Taken for $50 \%$ of the Drug to be Released $\left(\mathrm{T}_{50}\right)$, Mean Dissolution Time (MDT) and Dissolution Efficiency $\left(\mathrm{DE}_{120}\right)$

$\mathrm{MDT}$, T50 and DE characterize drug release rate from a dosage form. A lower MDT and T50 signifies rapid drug release from the dosage form (Afroz, Asaduzzaman, Rahman, \& Islam, 2011), while a higher DE indicates a faster drug release (Júnior et al., 2014). B8 had the lowest MDT and T50 as seen in Fig. 3, but B8 had the highest dissolution efficiency at $120 \mathrm{~min}$ as seen in Table 4, compared with all the other batches of tablets tested. This consistently signifies that batch B8 exhibited the best dissolution profile/ fastest drug release. The control batch had the lowest dissolution efficiency. There were significant differences in the $\mathrm{DE}_{120}$ between the formulated batches and the commercial brand when a oneway ANOVA was performed on the dissolution efficiencies of the griseofulvin tablets at a $95 \%$ confidence interval.Anderson et al. (1998) suggested that a mean difference of $\pm 10 \%$ between a test and reference dissolution profile signify similarity in dissolution characteristics. Table 5 indicates that batches B7, B8 and B9 have similar dissolution profile with the commercial brand as they have mean $\mathrm{DE}_{120}$ differences of $1.9,-10.2$ and -4.08 respectively with the commercial brand. B1, B4 and B6 show similarities in dissolution profile and that of the control batch as their mean $\mathrm{DE}_{120}$ with the control batch were $-1.42,-5.8$ and -4.68 respectively.

\subsubsection{Fit Factors (f2 and f1):}

A similarity factor (f2) between 50 to 100 signify similarities between test and reference batches while a difference factor between 0 to 15 similarly indicate similarities in dissolution profiles of test and reference batches (Anderson et al., 1998; Islam et al., 2011; Sakina et al., 2013). f2 values of B1, B4 and B6 as shown in Table 5 indicate similarities with the control batch as their values fell within 50 to 100 . As stated earlier, the f2 value is more reliable than the f1 value (Júnior et al., 2014; Yuksel et al., 2000). None of the formulated batches of griseofulv in showed similarities with the commercial brand with regards to the fit factors as seen in Table 5.

\begin{tabular}{|c|c|c|}
\hline Batches & Mean (\%) & Standard Deviation \\
\hline Ctrl & $24.42^{*}$ & 0.05 \\
\hline B1 & $25.84^{*}$ & 0.06 \\
\hline B4 & $30.22^{*}$ & 0.00 \\
\hline B5 & $40.54^{*}$ & 0.03 \\
\hline B6 & $29.09^{*}$ & 0.05 \\
\hline B7 & $62.91^{*}$ & 0.01 \\
\hline B8 & $75.76^{*}$ & 0.02 \\
\hline B9 & $69.65^{*}$ & 0.03 \\
\hline Brand & 64.35 & 0.03 \\
\hline
\end{tabular}

Table 4: A One -Way ANOVA Analysis of the Dissolution Efficiency $\left(\mathrm{DE}_{120}\right)$ of the Formulated Batches and the Commercial Brand at $\mathrm{P}<0.05$

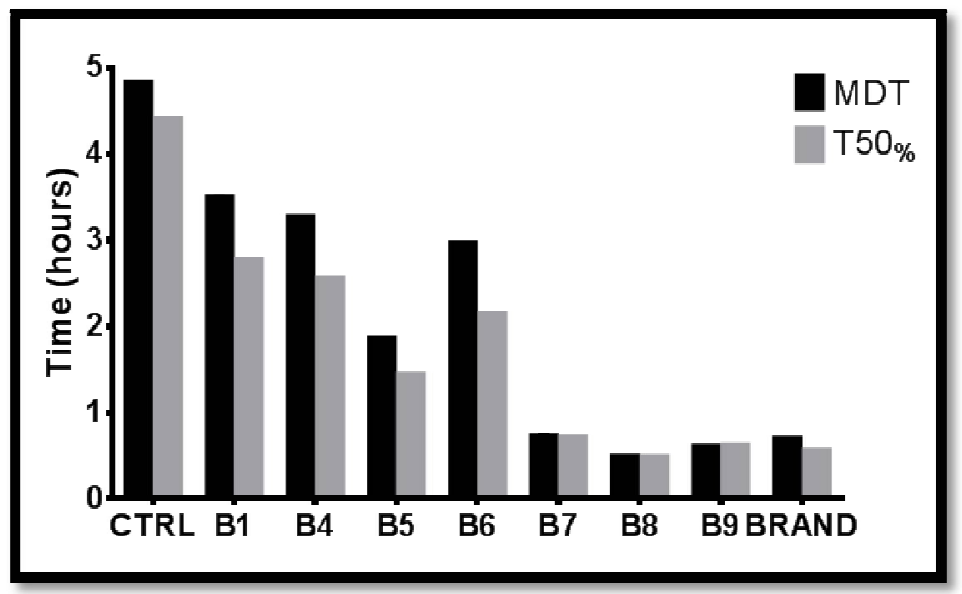

Figure 3: Time Required for 50\% Drug Release $\left(\mathrm{T}_{50 \%}\right)$ and Mean Dissolution Time (MDT) of the Formulated Batches and the Commercial Brand

Key: Ctrl (No Surfactant), Brand (Commercial Brand), B1 (2.5\% KHS 15), B4 (1\% SLS), B5 (1.5 SLS), B6 (2\% SLS), B7 (6.25\% PEG 4000), B8 (12.5\% PEG 4000), B9 (15\% PEG 4000) 


\begin{tabular}{|c|c|c|c|c|c|c|}
\hline & $\mathbf{f 1}^{\mathbf{a}}$ & $\mathbf{f 2}^{\mathbf{a}}$ & $\begin{array}{c}\text { Mean Difference } \\
\text { in DE (\%) }^{\mathbf{a}}\end{array}$ & $\mathbf{f 1}^{\mathbf{b}}$ & $\mathbf{f 2}^{\mathbf{b}}$ & $\begin{array}{c}\text { Mean Difference } \\
\text { in DE(\% }^{\mathbf{b}}\end{array}$ \\
\hline Ctrl & & & & 61.41 & 19.33 & -41.41 \\
\hline B1 & 14.76 & 64.38 & -1.42 & 60.84 & 19.61 & 39.72 \\
\hline B4 & 24.8 & 58.98 & -5.8 & 53.62 & 22.09 & 35.34 \\
\hline B5 & 62.38 & 38.9 & -16.13 & 38.59 & 27.74 & 25.01 \\
\hline B6 & 27.51 & 54.34 & -4.68 & 56.65 & 20.99 & 36.46 \\
\hline B7 & 140.66 & 20.25 & -39.24 & 21.95 & 34.57 & 1.9 \\
\hline B8 & 188.34 & 14.93 & -51.34 & 32.62 & 31.43 & -10.2 \\
\hline B9 & 163 & 17.09 & -45.22 & 30.98 & 31.9 & -4.08 \\
\hline Brand & 158.43 & 19.62 & 41.41 & & & \\
\hline
\end{tabular}

Table 5: Fit Factors and Mean Difference in Dissolution Efficiency between the Control Batch and the Other Griseofulvin

Tablets and Between the Commercial Brand and the Formulated Griseofulvin Tablets

$\mathrm{A}=$ Comparison with the Control Batch, $\mathrm{B}=$ Comparison with the Commercial Brand

Key: Ctrl (No Surfactant), Brand (Commercial Brand), B1 (2.5\% KHS 15), B4 (1\% SLS), B5 (1.5 SLS), B6 (2\% SLS), B7 (6.25\% PEG 4000), B8 (12.5\% PEG 4000), B9 (15\% PEG 4000)

\subsubsection{Model Dependent Comparison}

\subsubsection{Weibull Dissolution Model}

The Weibull parameters used for comparison were the time scale parameter or apparent rate constant $(\alpha)$, the shape parameter $(\beta)$ and the time it takes $63.2 \%$ of the drug to be dissolved (Td). The equation between all 3 Weibull parameters is $\alpha=(\mathrm{Td}){ }^{\beta}$. The Weibull model can easily be applied to all dissolution profiles (Costa \& Lobo, 2001). Lower $\alpha$ and Td value indicate faster drug release while a higher $\alpha$ and Td value indicate slower drug release. B8 had the lowest $\alpha$ and Td values of 0.53 and $0.50 \mathrm{hr}$ respectively indicating faster drug release while the control batch had the highest $\alpha$ and Td values as shown in Table 6 signifying slowest drug release. The Shape parameter $(\beta)$ describes the shape of the dissolution curve. $\beta<1$ shows a parabolic curve. It also describes an initial increase in the rate of drug release but an eventual decrease in drug release as time increases. $\beta>1$ shows a sigmoidal curve, also indicating an increase in the rate of drug release with the increase in time. While $\beta=1$ shows an exponential curve, which signifies a first-order kinetics (Papadopoulou, Kosmidis, Vlachou, \& Macheras, 2006; Patel, Chauhan, Patel, Patel, \& Patel, 2012; Weibull, 1951).

\begin{tabular}{|c|c|c|c|c|}
\hline Batches & A & B & Shape of Curve & T $_{\mathbf{d}}$ (Hours) \\
\hline CTRL & $3.40 \pm 0.01^{* * * *}$ & $0.10 \pm 0.00$ & Parabolic & $253375.73 \pm 21701.87^{* * * *}$ \\
\hline B1 & $3.08 \pm 0.01^{* * * *}$ & $0.37 \pm 0.00$ & Parabolic & $21.44 \pm 0.23$ \\
\hline B4 & $2.59 \pm 0.00^{* * * *}$ & $0.26 \pm 0.00$ & Parabolic & $41.50 \pm 0.84$ \\
\hline B5 & $1.73 \pm 0.00^{* * * *}$ & $0.43 \pm 0.00$ & Parabolic & $3.61 \pm 0.04$ \\
\hline B6 & $2.65 \pm 0.01^{* * * *}$ & $0.53 \pm 0.00$ & Parabolic & $6.28 \pm 0.09$ \\
\hline B7 & $0.86 \pm 0.00^{* * * *}$ & $0.90 \pm 0.00$ & Parabolic & $0.85 \pm 0.00$ \\
\hline B8 & $0.53 \pm 0.00^{* * * *}$ & $0.91 \pm 0.00$ & Parabolic & $0.50 \pm 0.00$ \\
\hline B9 & $0.65 \pm 0.00^{* * * *}$ & $1.00 \pm 0.00$ & Exponential & $0.65 \pm 0.00$ \\
\hline BRAND & $0.92 \pm 0.00$ & $0.15 \pm 0.00$ & Parabolic & $0.59 \pm 0.00$ \\
\hline
\end{tabular}

Table 6: Weibull Parameters for Characterizing the Dissolution Curves

Key: A= Time Scale/Apparent Rate Constant, B= Shape Parameter (Characterizing The

Shape Of Curve), $T_{d}=$ Mean Time Interval For 63.2\% Of The Drug To Be Dissolved, ${ }^{*}=$ Indicates Significant Difference Between

The Commercial Brand And The Test (Formulated Batches) At $\mathrm{P} \varangle 0.05$.

Ctrl (No Surfactant), Brand (Commercial Brand), B1 (2.5\% KHS 15), B4 (1\% SLS), B5 (1.5 SLS), B6 (2\% SLS), B7 (6.25\% PEG 4000), B8 (12.5\% PEG 4000), B9 (15\% PEG 4000)

All the batches of griseofulvin tablets except B9 had parabolic dissolution curves. B9 exhibited an exponential curve signifying a first-order kinetic. Using a one-way ANOVA to analyze the parameters, there were significant differences between the commercial brand and the formulated batches of griseofulvin (Table 6).

\begin{tabular}{|c|c|c|}
\hline Release Exponent (n) & Drug Transport Mechanism & Rate as a Function of Time \\
\hline $\mathrm{n} \varangle 0.45$ & Quasi-Fickian diffusion & $\mathrm{t}^{-0.5}$ \\
\hline 0.45 & Fickian diffusion & $\mathrm{t}^{-0.5}$ \\
\hline $0.45 \varangle \mathrm{n}<1.0$ & Anomalous (non-Fickian) transport & Zero order release \\
\hline 1.0 & Case II transport & $\mathrm{t}^{\mathrm{n}-1}$ \\
\hline Higher than 1.0 & Super Case-II transport & \\
\hline
\end{tabular}

Table 7: Korsmeyer -Peppas Interpretation of Release Exponent (N)

Source: (Chime, Onunkwo, \& Onyishi, 2013; Mesnukul, Yodkhum, Mahadlek, \& Phaechamud, 2010) 


\subsubsection{Korsmeyer-Peppas Model}

It is a semi-empirical model that studies the release mechanism of the drug with the aid of its release exponent (n). Its parameters used for dissolution profile comparison are the rate constant (Kkp) and the release exponent (n). Table 7 explains the release mechanism values of $n$. The value of $n$ in Table 8, shows that the commercial brand, the control batch and batches B1 to B6 all exhibited a quasi-Fickian diffusion. A quasi-Fickian release is predominantly diffusional with a little case of relaxation. While batches B7 to B9 exhibited an anomalous release mechanism which follows both an erosion controlled and diffusion release mechanisms(Basak, Kumar, \& Ramalingam, 2008; Chime et al., 2013; Cojocaru et al.,, 2015; Huang et al.,, 2013). Using one-way ANOVA to analyze the Korsmeyer's parameters of all the batches show no similarities between the formulated batch and the commercial brand (Table 8).

\begin{tabular}{|c|c|c|c|c|}
\hline Batches & Kkp & $\mathbf{N}$ & $\begin{array}{c}\text { Diffusional } \\
\text { mechanism }\end{array}$ & $\mathbf{T}_{\mathbf{5 0}}$ \\
\hline CTRL & $25.49 \pm 0.05^{* * * *}$ & $0.09 \pm 0.00$ & Quasi - Fickian & $2263.53 \pm 136.37^{* * * *}$ \\
\hline B1 & $27.64 \pm 0.07^{* * * *}$ & $0.33 \pm 0.00$ & Quasi - Fickian & $6.18 \pm 0.06$ \\
\hline B4 & $31.98 \pm 0.00^{* * * *}$ & $0.22 \pm 0.00$ & Quasi - Fickian & $7.68 \pm 0.09$ \\
\hline B5 & $43.53 \pm 0.04^{* * * *}$ & $0.34 \pm 0.00$ & Quasi - Fickian & $1.50 \pm 0.01$ \\
\hline B6 & $31.21 \pm 0.07^{* * * *}$ & $0.44 \pm 0.00$ & Quasi - Fickian & $2.81 \pm 0.03$ \\
\hline B7 & $66.20 \pm 0.05^{* * * *}$ & $0.57 \pm 0.00$ & Anomalous & $0.61 \pm 0.00$ \\
\hline B8 & $80.56 \pm 0.04^{* * * *}$ & $0.46 \pm 0.00$ & Anomalous & $0.34 \pm 0.00$ \\
\hline B9 & $74.06 \pm 0.03^{* * * *}$ & $0.53 \pm 0.00$ & Anomalous & $0.48 \pm 0.00$ \\
\hline Brand & $66.50 \pm 0.02$ & $0.11 \pm 0.00$ & Quasi - Fickian & $0.07 \pm 0.00$ \\
\hline
\end{tabular}

Table 8: Korsmeyer- Peppas Parameters for Characterizing the Dissolution Curves

Key: Kkp $=$ Rate Constant, N=Release Exponent, $\mathrm{T}_{50}=$ Mean Time Interval for 50\% of the Drug to Be Dissolved, $*$ Depicts

Significant Difference between Formulated Batches and the Commercial Brand

Key: Ctrl (No Surfactant), Brand (Commercial Brand), B1 (2.5\% Khs 15), B4 (1\% Sls), B5 (1.5 Sls), B6 (2\% Sls), B7 (6.25\% Peg 4000), B8 (12.5\% Peg 4000), B9 (15\% Peg 4000)

\begin{tabular}{|c|c|c|c|}
\hline $\begin{array}{c}\text { Release Exponent } \\
\text { (N) }\end{array}$ & $\begin{array}{c}\text { Weibull's Parameter } \\
\text { (B) }\end{array}$ & Drug Transport Mechanism & Rate as a Function of Time \\
\hline & & & \\
\hline $\mathrm{n} \varangle 0.45$ & & Quasi-Fickian diffusion & $\mathrm{t}^{-0.5}$ \\
\hline 0.45 & $\beta \leq 0.75$ & Fickian diffusion & $\mathrm{t}^{-0.5}$ \\
\hline $0.45 \varangle \mathrm{n}<1.0$ & $0.75<\beta<1$ & $\begin{array}{c}\text { Anomalous (non-Fickian) } \\
\text { transport }\end{array}$ & Zero order release \\
\hline 1.0 & & Case II transport & $\mathrm{t}^{\mathrm{n}-1}$ \\
\hline Higher than 1.0 & $\beta>1$ & Super Case-II transport & \\
\hline
\end{tabular}

Table 9: Relationship between Korsmeyer -Peppas Release Exponent (N) and Weibull's Parameter (B)

(Chime Et Al., 2013; Mesnukul Et Al., 2010; Papadopoulou Et Al., 2006)

\section{Discussion}

The results of $\mathrm{T}_{50}, \mathrm{MDT}, \mathrm{DE}_{120}$, Weibull's parameters ( $\alpha$ and $\mathrm{Td}$ ) show that $\mathrm{B} 8$ consistently had the best dissolution profile. While the control batch had the poorest dissolution profile. The addition of surfactants into the formulation improved the dissolution profile of the griseofulvin tablets as the control batch formulated without surfactants showed the poorest dissolution profile having the lowest $\mathrm{DE}_{120}$, the highest $\mathrm{MDT}$, highest $\mathrm{T}_{50}$ values and highest $\alpha$ and $\mathrm{Td}$ values. Surfactants when introduced to a system at low concentration, usually adsorb to the interface and reduce interfacial tension thereby increasing the solubility and dissolution rate of a drug. When present at a level above the CMC, micelles are formed which greatly aid drug solubility and dissolution. From several works carried out (Granero et al., 2005; Incecayir, 2015; Rangel-Yagui, Pessoa Jr, \& Tavares, 2005; Takai, Takayama, Nambu, \& Nagai, 1984), it has been noted that increased solubility and dissolution rates of poorly soluble drugs by surfactants is mainly due to micellar solubility, which occurs when surfactants are present in levels above CMC in a formulation or the dissolution medium. During micellar solubilization, poorly soluble drugs are entrapped in the micelles of the surfactant, thereby aiding its dissolution and solubility(Incecayir, 2015; Savjani, Gajjar, \& Savjani, 2012). Balakrishnan, Rege, Amidon, and Polli (2004), Graneroet al. (2005) and Ofoefule and Chukwu (2000); Ofoefule \& Chukwu, (2001) noticed the dual effect of surfactants on the active drug in dosage formulations. It was noticed that as the concentration of surfactants increased, the micelle formed would be increased, more drugs would be entrapped in the micelles, the increased micelles lead to increased viscosity of the medium thereby slowing the migration of the drug particles from the dosage form to the medium (Balakrishnan et al., 2004). This was also observed in this study that as the concentration of a particular surfactant increased, the dissolution rate of the drug increased but on more addition of the surfactants, dissolution rate decreases (Fig. 1 to Fig. 3, Table 3 and Table 4). From the results, PEG 4000 was the best surfactant for enhancing the dissolution of griseofulvin, especially at $12.5 \%$. The polyethylene part of PEG is the site of drug solubilization and it is responsible for enclosing the aqueous insoluble drug (Elworthy \& Lipscomb, 1968, 1969). The longer the polyoxyethylene chain, the more the drug enclosed, 
therefore an expected increase in dissolution(Bolourchian, Mahboobian, \& Dadashzadeh, 2013; Janssens, Denivelle, Rombaut, \& Van den Mooter, 2008).

Fig. 1 shows all the batches including the commercial brand having a bi-phasic dissolution curve. The first phase is a burst release which could be as a result of the release of the active drugs not entrapped in the surfactant micelle. The second phase of release which is gradual may be as a result of the slow diffusion of the active drug from the surfactants' micelle.

\subsection{Comparison of In -Vitro Dissolution Profiles}

Different methods were used in comparing the dissolution profiles of all the batches of tablets. The graphical method, though not as precise as the other methods used, can be used as a first step in comparing dissolution profiles(O'hara, Dunne, Butler, Devane, \& Group, 1998). The graphs in Fig. 1 and Fig. 2 show similarities in dissolution profiles amongst ctrl batch, B1, B4 and B6. Also, similarities in the dissolution profile are seen mostly between the commercial brand and the batch B7. Amongst the commercial brand, B7 and B9, there is similarity in dissolution profile at the 30th and 40th minute. MANOVA analysis conducted showed similarities mostly between the commercial brand and batch B7. Further analysis using t-test confirmed the strong similarities between the commercial brand and the batch B7. The control batch also showed no significant difference in dissolution amongst the ctrl batch, B1 and B6. Dissolution efficiency ( $\mathrm{DE}_{120}$ ) using Anderson et al. (1998) method, similarities in dissolution profiles are also seen amongst the commercial brand, B7, B8 and B9. Similarities also exist amongst the control batch, B1, B4 and B6. The similarity factor (f2) shows similarities amongst B1, B4, B6 and the commercial brand. No similarities are shown between the commercial brand and any of the formulated tablet batches.

Some similarities seen in dissolution profiles between the commercial brand and batches B7 and B9 as observed in Fig. 1, Fig. 2c, Table 3 and the mean difference in DE (Table 5) show the effectiveness of PEG 4000 in enhancing the dissolution of griseofulvin tablets more than the other surfactants used. A higher dissolution efficiency indicates a higher bioavailability in vivo (Júnior et al., 2014). This then indicates in vivo, the tablets formulated with PEG 4000 would have higher bioavailability compared with the other formulations. The seen similarities of B1, B4 and B6 with the control batch seen in Fig. 1, Fig. 2b and Table 5, shows that even though KHS 15 and SLS improved the dissolution of griseofulvin from the tablets, they did not give a dramatic improvement in the dissolution of griseofulvin. This corresponds to the observation made by Umeh, Azegba, and Ofoefule (2013) that SLS did not dramatically increase drug release from Fulcin ${ }^{\circledR}$. The work carried out even described the retardant effect of SLS on the dissolution of hydrochlorothiazide. KHS 15 is a semi-solid at room temperature, therefore it softened the griseofulvin tablets at increased concentrations after $2.5 \%$. Maybe a treatment of KHS 15 with an adsorbent might improve its quality as an excipient in tablet formulation.

Using the fit factors (f2 and f1), which is an FDA approved method of dissolution profile comparisons, to compare the profiles of the formulated batches with the commercial brand showed no similarities.

Also using the model-dependent method (Weibull's and Korsmeyer's models) for dissolution profile comparison and applying a two-way ANOVA analysis followed by a post-hoc Turkey test on the models' parameters, showed no similarities between the commercial brand and the formulated batches of griseofulvin.

\subsection{Release Mechanism}

The mathematical models used (Weibull and Korsemeyer's models) characterize the release patterns of the batches of tablets. Following the Weibull's model, all the batches exhibited a parabolic curve except B9 which exhibited an exponential curve signifying that batch B9 exhibits a first order kinetics while the other batches of tablets would show an initial increase in the rate of drug release but an eventual decrease in drug release as time increases (Papadopoulou et al., 2006).

It was also noticed using the Korsemeyer's model (n) parameter, that the batches formulated with SLS and KHS 15 exhibited a quasi - Fickian release method while PEG 4000 showed anomalous release mechanism (Table 8). SLS has been seen to promote Fickian diffusion (Razzak, Khan, Hossain, Anika, \& Moon, 2012). PEG has been observed to encourage erosion release mechanism and this is because it allows much ingress of the dissolution medium into the tablet creating pores where it dissolved thereby leading to erosion of the tablet (Efentakis, Al-Hmoud, Buckton, \& Rajan, 1991).

The Table 9 above shows that the drug release information given by the Korsemeyer's and Weibull's models are identical as their $\mathrm{n}$ and $\beta$ parameters respectively give same release patterns as Fickian diffusion for the commercial brand, control batch, batches B1 - B6. B7 and B8 would give anomalous release mechanism according to $\beta$ value, B9 would have a complex release mechanism.

\section{Conclusion}

This research was carried out to evaluate the effect of the application of the surfactants- KHS 15, SLS and PEG 4000 on the dissolution characteristics of griseofulvin and compare such effects with a commercial brand of griseofulvin whichserved as the reference standard. The wet granulation method was used in granulating the various batches of griseofulvin granules. Ten (10) batches of griseofulvin were obtained thus: Control batch (containing no surfactants), B1 (2.5\% KHS 15), B2 (5.0\% KHS15), B3(10.0\% KHS 15), B4 (1\% SLS), B5 (1.5\% SLS), B6(2.5\% SLS), B7 (6.25\% PEG 4000), B8 (12.5\% PEG 4000) and B9 (15\% PEG 4000). The introduction of surfactants into the formulations generally improved the dissolution of griseofulvin. Tablets containing PEG 4000 exhibited the best dissolution characteristics indicating that PEG 4000 is the best surfactant in the concentration range of $6.25 \%$ to $15 \%$ compared to the other surfactants, Kolliphor ${ }^{\circledR}$ HS 15 and SLS. B8 formulated with $12.5 \%$ of PEG 4000 had the best dissolution profile compared with all the other formulations. B7 showed the most similarities with the commercial brand than other batches. 
From all the methods used in comparing the dissolution profiles of the tablets, it can be seen that though the graphical method is not conclusive, it gives an idea of similarities in dissolution profiles. Here the graphs showed that the commercial brand and B7 exhibited similarities in their dissolution profiles, this is identical to the results obtained by the MANOVA analysis and the dissolution efficiency analysis. The f1 and f2 statistical method, though the approved method by FDA, easily dismisses some similarities between dissolution profiles as it never showed any similarities between the commercial brand and B7 even as other methods pointed to such similarities.

It would be advisable to compare dissolution profiles with several methods, not only the fit factors. As there would be available more information for good judgement.

\section{References}

i. Afroz, A., Asaduzzaman, M., Rahman, M. R. \& Islam, S. A. (2011). Development and evaluation of muco-adhesive ciprofloxacin bi-layer tablet for extended drug release. Asian J. Pharm. Res, 1(3), 64-68.

ii. Anderson, N., Bauer, M., Boussac, N., Khan-Malek, R., Munden, P., \& Sardaro, M. (1998). An evaluation of fit factors and dissolution efficiency for the comparison of in vitro dissolution profiles. Journal of pharmaceutical and biomedical analysis, 17(4-5), 811-822.

iii. Balakrishnan, A., Rege, B. D., Amidon, G. L., \& Polli, J. E. (2004). Surfactant-mediated dissolution: contributions of solubility enhancement and relatively low micelle diffusivity. Journal of pharmaceutical sciences, 93(8), 20642075.

iv. Basak, S. C., Kumar, K. S., \& Ramalingam, M. (2008). Design and release characteristics of sustained release tablet containing metformin HCl. Revista Brasileira de Ciências Farmacêuticas, 44(3), 477-483.

v. Beers, M. H., Fletcher, A. J., Jones, T., Porter, R., Berkwitz, M., \& Kaplan, J. (2003). The Merck manual of medical information (2nd ed.). New York: Pocket Books.

vi. Bolourchian, N., Mahboobian, M. M., \& Dadashzadeh, S. (2013). The effect of PEG molecular weights on dissolution behavior of Simvastatin in solid dispersions. Iranian journal of pharmaceutical research: IJPR, 12 (Suppl), 11.

vii. British Pharmacopoeia. (2009). Griseofulvin. London: The Stationary Office

viii. Chaumeil, J. (1998). Micronization: a method of improving the bioavailability of poorly soluble drugs. Methods and findings in experimental and clinical pharmacology, 20(3), 211-216.

ix. Chiang, P.-C., Cui, Y., Ran, Y., Lubach, J., Chou, K.-J., Bao, L., . . Sambrone, A. (2013). In vitro and in vivo evaluation of amorphous solid dispersions generated by different bench-scale processes, using griseofulvin as a model compound. The AAPSjournal, 15(2), 608-617.

x. Chime, S., Onunkwo, G., \& Onyishi, I. (2013). Kinetics and mechanisms of drug release from swellable and non swellable matrices: a review. Res J Pharm Biol Chem Sci, 4(2), 97-103.

xi. Chiou, W. L., \& Riegelman, S. (1971). Absorption characteristics of solid dispersed and micronized griseofulvin in man. Journal of pharmaceutical sciences, 60(9), 1376-1380.

xii. Cojocaru, V., Ranetti, A. E., Hinescu, L. G., Ionescu, M., Cosmescu, C., Poștoarcă, A. G., \& Cinteză, L. O. (2015). Formulation and evaluation of in vitro release kinetics of Na3CaDTPA decorporation agent embedded in microemulsion-based gel formulation for topical delivery. Farmacia, 63(5), 656-664.

xiii. Collier, P. S. (1984). The Interpretation ofIn Vivo Mean Dissolution Time Data Pharmacokinetics (pp. 403-406): Springer.

xiv. Costa, P., \& Lobo, J. M. S. (2001). Modeling and comparison of dissolution profiles. European Journal of Pharmaceutical Sciences, 13(2), 123-133.

xv. Efentakis, M., Al-Hmoud, H., Buckton, G., \& Rajan, Z. (1991). The influence of surfactants on drug release from a hydrophobic matrix. International Journal of Pharmaceutics, 70(1-2), 153-158.

xvi. El-Badry, M., Fetih, G., \& Fathy, M. (2009). Improvement of solubility and dissolution rate of indomethacin by solid dispersions in Gelucire 50/ 13 and PEG4000. Saudi Pharmaceutical Journal, 17(3), 217-225.

xvii. Elworthy, P., \& Lipscomb, F. (1968). Solubilization of griseofulvin by nonionic surfactants. Journal of Pharmacy and Pharmacology, 20(11), 817-824.

xviii. Elworthy, P., \& Lipscomb, F. (1969). The rate of dissolution of powdered griseofulvin at different stirring rates. Journal of Pharmacy and Pharmacology, 21(5), 273-276.

xix. FDA. (2000). Guidance for industry: waiver of in vivo bioavailability and bioequivalence studies for immediaterelease solid oral dosage forms based on a biopharmaceutics classification system. Food and Drug Administration, Rockville, MD.

xx. Gao, Y., Zuo, J., Bou-Chacra, N., Pinto, T. d. J. A., Clas, S.-D., Walker, R. B., \& Löbenberg, R. (2013). In vitro release kinetics of antituberculosis drugs from nanoparticles assessed using a modified dissolution apparatus. BioMed research international, 2013.

xxi. Gilbert, B. D. (2013). The United States Pharmacopeia 29/ National Formulary 24. Monograph Development Antibiotics, 1027.

xxii. Granero, G. E., Ramachandran, C., \& Amidon, G. L. (2005). Dissolution and solubility behavior of fenofibrate in sodium lauryl sulfate solutions. Drug Development and Industrial Pharmacy, 31(9), 917-922.

xxiii. Huang, W., Shi, Y., Wang, C., Yu, K., Sun, F., \& Li, Y. (2013). Using spray-dried lactose monohydrate in wet granulation method for a low-dose oral formulation of a paliperidone derivative. Powder Technology, 246, 379394.

xxiv. Incecayir, T. (2015). The effects of surfactants on the solubility and dissolution profiles of a poorly water-soluble basic drug, carvedilol. Die Pharmazie-An International Journal of Pharmaceutical Sciences, 70(12), 784-790. 
xxv. Islam, S., Islam, S., Shahriar, M., \& Dewan, I. (2011). Comparative in vitro dissolution study of Aceclofenac Marketed Tablets in Two Different Dissolution Media by Validated Analytical Method.

xxvi. Janssens, S., Denivelle, S., Rombaut, P., \& Van den Mooter, G. (2008). Influence of polyethylene glycol chain length on compatibility and release characteristics of ternary solid dispersions of itraconazole in polyethylene glycol/ hydroxypropylmethylcellulose 2910 E5 blends. European Journal of Pharmaceutical Sciences, 35(3), 203210.

xxvii. Júnior, S., de Freitas, A., Barbosa, I. S., Santos, V. L. d., Silva, R. L., \& Caetite Junior, E. (2014). Test of dissolution and comparison of in vitro dissolution profiles of coated ranitidine tablets marketed in Bahia, Brazil. Brazilian Journal of Pharmaceutical Sciences, 50(1), 83-89.

xxviii. Kassaye, L., \& Genete, G. (2013). Evaluation and comparison of in-vitro dissolution profiles for different brands of amoxicillin capsules. African health sciences, 13(2), 369-375.

xxix. Khalafalla, N., Elgholmy, Z., \& Khalil, S. (1980). Bioavailability of different brands of griseofulvin tablets and its correlation to dissolution data. Die Pharmazie, 35(8), 482-484.

xxx. Lee, E.-J., Lee, S.-W., Choi, H.-G., \& Kim, C.-K. (2001). Bioavailability of cyclosporin A dispersed in sodium lauryl sulfate-dextrin based solid microspheres. International Journal of Pharmaceutics, 218(1-2), 125-131.

xxxi. Madelung, P., Bertelsen, P., Jacobsen, J., Müllertz, A., \& Østergaard, J. (2017). Dissolution enhancement of griseofulvin from griseofulvin-sodium dodecyl sulfate discs investigated by UV imaging. Journal of Drug Delivery Science and Technology, 39, 516-522.

xxxii. McGinity, J., Ku, C.-T., Bodmeier, R., \& Harris, M. (1985). Dissolution and uniformity properties of ordered mixes of micronized griseofulvin and a directly compressible excipient. Drug Development and Industrial Pharmacy, 11(4), 891-900.

xxxiii. Medina, J. R., Salazar, D. K., Hurtado, M., Cortes, A. R., \& Domínguez-Ramírez, A. M. (2014). Comparative in vitro dissolution study of carbamazepine immediate-release products using the USP paddles method and the flowthrough cell system. Saudi Pharmaceutical Journal, 22(2), 141-147.

xxxiv. Mesnukul, A., Yodkhum, K., Mahadlek, J., \& Phaechamud, T. (2010). Characterization of indomethacin release from polyethylene glycol tablet fabricated with mold technique. Indian journal of pharmaceutical sciences, 72(1), 92.

xxxv. Nyström, C., \& Westerberg, M. (1986). The use of ordered mixtures for improving the dissolution rate of low solubility compounds\&. Journal of Pharmacy and Pharmacology, 38(3), 161-165.

xxxvi. O'hara, T., Dunne, A., Butler, J., Devane, J., \& Group, I. C. W. (1998). A review of methods used to compare dissolution profile data. Pharmaceutical Science \& Technology Today, 1(5), 214-223.

xxxvii. Ofoefule, S. I., \& Chukwu, A. (2000). The effects of primogel on the release of frusemide from encapsulated granules. Acta pharmaceutica, 50(2), 157-162.

xxxviii. Ofoefule, S. I., \& Chukwu, A. (2001). Effects of polyethyleneglycol 4000 and sodium lauryl sulphate on the release of hydrochlorothiazide embedded in the dika fat matrix. Acta pharmaceutica, 51(3), 233-239.

xxxix. Ong, S. G. M., Ming, L. C., Lee, K. S., \& Yuen, K. H. (2016). Influence of the encapsulation efficiency and size of liposome on the oral bioavailability of griseofulvin-loaded liposomes. Pharmaceutics, 8(3), 25.

xl. Papadopoulou, V., Kosmidis, K., Vlachou, M., \& Macheras, P. (2006). On the use of the Weibull function for the discernment of drug release mechanisms. International Journal of Pharmaceutics, 309(1-2), 44-50.

xli. Pascoal, A., da Silva, P., \& Pinheiro, M. C. (2015). Drug dissolution profiles from polymeric matrices: Data versus numerical solution of the diffusion problem and kinetic models. International Communications in Heat and Mass Transfer, 61, 118-127.

xlii. Patel, H., Chauhan, P., Patel, K., Patel, B., \& Patel, P. (2012). Formulation and Evaluation of Effervescent Tablet of Paracetamol and Ibuprofen. Int. J. Pharm. Res. Sch, 2(1), 509-520.

xliii. Phanchaxari, M., Kaushik, S., \& Telsang, S. (2011). Enhancement of solubility and dissolution property of griseofulvin by nanocrystallization. International Journal of Drug Development and Research, 3(2).

xliv. The Pharmaceutical Codex (1979). (11 edition ed. Vol. 69). One Lambeth High St., London SE1 7JN, England: The Pharmaceutical Press, .

xlv. Podczeck, F. (1993). Comparison of in vitro dissolution profiles by calculating mean dissolution time (MDT) or mean residence time (MRT). International Journal of Pharmaceutics, 97(1-3), 93-100.

xlvi. Rangel-Yagui, C. O., Pessoa Jr, A., \& Tavares, L. C. (2005). Micellar solubilization of drugs. J. Pharm. Pharm. Sci, 8(2), 147-163.

xlvii. Razvi, N., Siddiqui, S. A., \& Khan, L. G. (2005). The effect of surfactant on the dissolution rate of ibuprofen tablets. IntI. Chern. Pharm. Med.J, 2(1), 213-216.

xlviii. Razzak, M., Khan, F., Hossain, M., Anika, T., \& Moon, S. A. (2012). Impact of sodium lauryl sulphate on the release of carbamazepine from methocel K15M CR based matrix tablets. Bangladesh Pharm J, 15(1), 79-82.

xlix. Sakina, F., Usman, S., \& Naeem, M. I. (2013). Statistical evaluation of in-vitro dissolution profiles of different brands of Simvastatin $20 \mathrm{mg}$ tablets available in local market of Karachi. Int, J, pharm. pharm. Sci, 5(3), 622-626.

1. Sanford Bolton. . (1997). Pharmaceutical Statistics, Practical and Clinical Applications. New York: Marcel Dekker.

li. Savjani, K. T., Gajjar, A. K., \& Savjani, J. K. (2012). Drug solubility: importance and enhancement techniques. ISRN pharmaceutics, 2012.

lii. Schlossberg, D. L., \& Samuel, R. (2017). Antibiotics Manual: A Guide to Commonly Used Antimicrobials: Wiley.

liii. Simionato, L. D., Petrone, L., Baldut, M., Bonafede, S. L., \& Segall, A. I. (2018) . Comparison between the dissolution profiles of nine meloxicam tablet brands commercially available in Buenos Aires, Argentina. Saudi Pharmaceutical Journal, 26(4), 578-584. 
liv. Soni, T., \& Chotai, N. (2010). Assessment of dissolution profile of marketed aceclofenac formulations. Journal of Young Pharmacists, 2(1), 21-26.

lv. Takai, T., Takayama, K., Nambu, N., \& Nagai, T. (1984). Factors affecting the dissolution of griseofulvin dispersed in various water-soluble polymers. Chemical and Pharmaceutical Bulletin, 32(5), 1936-1941.

lvi. Umeh, O., Azegba, J., \& Ofoefule, S. (2013). Effect of hydrophilic diluents on the release profile of griseofulvin from tablet formulations. Indian journal of pharmaceutical sciences, 75(6), 726.

lvii. Weibull, W. (1951). A statistical distribution function of wide applicability. Journal of applied mechanics, 18(3), 293-297.

lviii. WHO. (2001). IARC monographs on the evaluation of carcinogenic risks to humans. Volume 79: Some thyrotropic agents: World Health Organization.

lix. Yuksel, N., Kanik, A., \& Baykara, T. (2000). Comparison of in vitro dissolution profiles by ANOVA-based, modeldependent and -independent methods (Vol. 209).

lx. Zhang, Y., Huo, M., Zhou, J., Zou, A., Li, W., Yao, C., \& Xie, S. (2010). DDSolver: an add-in program for modeling and comparison of drug dissolution profiles. The AAPSjournal, 12(3), 263-271.

lxi. Zili, Z., Sfar, S., \& Fessi, H. (2005). Preparation and characterization of poly-e-caprolactone nanoparticles containing griseofulvin. International Journal of Pharmaceutics, 294(1-2), 261-267. 